\section{Comparative Economic Efficiency of Four Peach Production Systems in California}

\author{
T.M. DeJong, W. Tsuji, J.F. Doyle, and Y.L. Grossman ${ }^{1}$ \\ Department of Pomology, University of California, One Shields Avenue, \\ Davis, CA 95616
} Additional index words. Prunus persica, pruning, training systems, yield, high-density
plantings

\begin{abstract}
A clingstone peach (Prunus persica L. Batsch 'Ross' on 'Nemaguard' rootstock) orchard was established at the Univ. of California Kearney Agricultural Center, Parlier, for evaluating the economic efficiency of three high-density planting systems in comparison with the conventional Open Vase system. The orchard contained four replicate plots $(0.80 \mathrm{ha} / \mathrm{plot})$, each containing four different planting systems. The four planting/training systems (in-row spacing given first) were: the "KAC-V" (a perpendicular V system spaced $2.0 \times 5.5 \mathrm{~m}, 919$ trees/ha); the "HiD KAC V" (spaced $1.8 \times 4.6 \mathrm{~m}, 1196$ trees/ha); the "Cordon" (spaced $2.4 \times 4.0 \mathrm{~m}$, with perpendicular harvest drives $4.8 \mathrm{~m}$ every $22 \mathrm{~m}$ and tree height limited to $2.5 \mathrm{~m}, 919$ trees/ha); and the "Open Vase" (spaced 6.1 $\times 5.5 \mathrm{~m}, 299$ trees/ ha). All system-specific costs and crop yields were recorded annually on each subplot for the first 5 years. Although the Cordon system had the highest yields in the second year, the $V$ systems had the highest returns after 5 years. Cumulative costs were: HiD KAC-V system $>$ KAC-V $\geq$ Cordon $>$ Open Vase. The system that was designed to maintain tree height $<2.5 \mathrm{~m}$ (Cordon) tended to be less profitable than the $\mathrm{V}$ systems because of modest crop yields and high pruning costs that were not offset by increased harvest efficiency. In the last 3 years of the study, pruning, thinning, and harvesting accounted for the majority of the system-specific costs.
\end{abstract}

During the past 20 years, the trend toward higher density orchard systems has increased for many temperate fruit and nut crops. Apple growers in most regions of the world have adopted high-density systems more rapidly than growers of many other fruit and nut species because traditional low-density apple systems are slow to come into full orchard production (5-8 years), and a range of sizecontrolling rootstocks has become available (Jackson et al., 1986).

The success with high-density apple plantings has stimulated researcher and grower interest in developing high-density systems for other tree species, especially peach. However, peach trees tend to be very vigorous, reach full bearing potential more quickly than apples (4-6 years, DeJong et al., 1994), and no widely adaptable size-controlling rootstocks are available. Numerous attempts have been made to deal with these constraints by developing training/pruning systems to accommodate the growth characteristics of peach when planted at close spacings. Several systems were initially developed in other countries (Bargioni et al., 1983, 1985; Chalmers et al., 1978;Erez, 1978; Hutton et al., 1987; Sansavini

Received for publication 18 Sept. 1997. Accepted for publication 23 July 1998. The cost of publishing this paper was defrayed in part by the payment of page charges. Under postal regulations, this paper therefore must be hereby marked advertisement solely to indicate this fact.

${ }^{1}$ Current address: Biology Dept., Beloit College, Beloit, WI 53511. et al., 1985) and then tested or adapted to conditions in the United States (Couvillon and Erez, 1979; Denby et al., 1988; Taylor, 1988). Many high-density systems can be more productive than conventional systems, particularly in the early life of the orchard. However, very few well-documented studies have compared the economic efficiencies of high-density systems with traditional systems. Highdensity apple systems are reportedly more profitable, particularly in Europe, but even those studies were based primarily on nonreplicated plots (Jackson et al., 1986; Stephens and Nicholson, 1978) or modeled data (Goedegebure, 1986; Parry 1982; van den Ende et al., 1987; Winter, 1986) rather than empirical experiments. There is even less information available regarding the profitability of high-density planting systems for peach.

During the 1980s, California growers began experimenting with two high-density systems for commercial peach production. In one system, evolved from research conducted more than a decade earlier by a grower (W. Salter) and known as the Cordon (or Salter) system (Rogers, 1986), the trees are encouraged to grow as vigorously as possible in the first season after planting. During midsummer of the first year, trees are pruned to two major branches that are then bent over and wrapped around a horizontal rope running down the tree row $\approx 1.5 \mathrm{~m}$ above the soil surface. These branches then become cordons from which fruit-producing branches emerge. Trees are planted $\approx 2.5 \mathrm{~m}$ in the row and 4 to $4.5 \mathrm{~m}$ between rows and maintained at a height of
$<2.5 \mathrm{~m}$. The primary objectives of this system are high yields early in the life of the orchard, and the elimination of ladders for pruning, fruit thinning, and harvesting.

The second system is the perpendicular "V" system (DeJong et al., 1994). This system is an adaptation of the Tatura Trellis system (Chalmers et al., 1978) but without a trellis. Systems similar to it are also referred to as "Y" systems in some regions of the world (Horton, 1988 ). Trees are generally spaced $\approx 2.0 \mathrm{~m}$ in the row and 5.0-6.0 $\mathrm{m}$ between rows with two primary scaffolds oriented perpendicular to the tree row. Tree height ranges up to $4.5 \mathrm{~m}$. The primary objectives of this system are high early yields and ease of orchard management (DeJong et al., 1994).

The conventional orchard system for growing peaches in California is the Open Vase system, which still accounts for most of the total acreage (Micke et al., 1980). Although there are numerous variations of this system, the trees generally have three to five primary scaffolds that are allowed to branch and form the shape of a large vase or goblet with an open center. Trees are planted at relatively low densities with 4.0 to $6.5 \mathrm{~m}$ between trees and between rows. Trees are allowed to grow to a height of 4.0 to $5.0 \mathrm{~m}$, depending on tree vigor and spacing.

The purpose of this study was to compare the profitability of these planting systems under California conditions. Records of all system-specific costs and tree productivity were maintained for the first 5 years after planting.

\section{Materials and Methods}

In Jan. 1990, a field research block of 'Ross' clingstone peaches on 'Nemaguard' rootstock was established at the Univ. of California Kearney Agricultural Center, Parlier. Each of four replicated plots of 0.80 ha contained four subplots ( 0.20 ha each) with different training/planting systems. The four systems (in-row spacing given first) were: the Cordon system $(2.4 \times 4.0 \mathrm{~m}$ with 4.8 -m-wide perpendicular drives spaced every $22 \mathrm{~m}$ down the rows, 919 trees/ha); a perpendicular V (KAC-V) system $(2.0 \times 5.5 \mathrm{~m}, 919$ trees/ha); a high-density perpendicular $\mathrm{V}$ (HiD KAC-V) system $(1.8 \times 4.6 \mathrm{~m}, 1196$ trees/ha), and standard Open Vase system $(6.1 \times 5.5 \mathrm{~m}, 299$ trees/ ha). Rows were oriented in a N-S direction.

The soil was a Hanford fine sandy loam. Prior to planting the soil was fumigated using 1-3 dichloropropene (Telone II at $374 \mathrm{~L} \cdot \mathrm{ha}^{-1}$ ), deep ripped, and leveled. In the first year after planting the field was furrow irrigated. After the first year, a slight berm $(\approx 15 \mathrm{~cm}$ high) was formed on each side of the tree row and the area between the berms was leveled and periodically flooded. Irrigation was scheduled to maintain $100 \%$ replacement of evapotranspiration requirements. The row middles were tilled the first year and subsequently mowed to control weeds. A weed-free strip $1 \mathrm{~m}$ wide was maintained in the tree row with combinations of contact and preemergence herbicides as deemed appropriate. Insects and diseases were controlled with pheromone confusion tech- 
niques and commercially used pesticides as needed.

Year one. Trees were hand planted on 9 Jan. 1990. Immediately after planting, trees were headed to a height of $\approx 0.5 \mathrm{~m}$ and tree wraps were placed on the lower $0.3 \mathrm{~m}$ of each tree.

Tree pruning and training operations during the first year differed greatly depending on the system. The Cordon system required the most training/pruning in the first year, primarily because of the rope trellis. The posts and rope were installed in mid-July and two shoots per tree were tied to the rope at the end of July to establish the cordons. At the time of tying, these shoots were not long enough to bridge the gap between trees, but they had begun to stiffen so that later tying would have caused limb breakage. Summer pruning after tying eliminated competition between vigorous shoots and the cordons. Trees that were too small to be tied in July were tied in September, and others that had not responded favorably were retied.

Initial scaffold selection in the two perpendicular V systems was made in the first week in May by selecting two strong shoots with the proper orientation, eliminating all shoots arising above them, and lightly heading the shoots coming off the trunk below the selected shoots. In August, the dominance of the previously selected shoots was reinforced by again heading or eliminating competing shoots and redirecting the growth of the selected scaffolds, as necessary, to maintain a proper orientation. We would have recommended selection of primary scaffolds in the Open Vase trees during the first growing season, but we chose not to do so because most commercial growers in California wait to prune first-leaf trees until the first dormant season.

Yeartwo. All systems were dormant pruned in mid-Dec. 1990. Dormant pruning in the Cordon system was relatively light because of the intensive summer pruning and limb tying done in the previous growing season. Low limbs and vertical water sprouts were removed and terminal shoots were thinned out. Pruning on the two $\mathrm{V}$ systems involved final selection of the two scaffolds, removal of all vertical shoots that might compete with the selected scaffolds, and thinning out the fruiting shoots on the upper half of the scaffolds. Pruning in the Open Vase system was relatively extensive because the trees had not been summer pruned and initial scaffold selection was accomplished at this time. The primary scaffolds that were selected were headed to a length of $\approx 1.0$ to $1.2 \mathrm{~m}$.

All four orchard systems were suckered on 9 Apr. 1991 by removing root suckers and shoots arising from within $0.3 \mathrm{~m}$ of soil. The Cordon system was summer pruned at the end of April and after harvest in August. During these prunings, rapidly growing, vigorous, upright shoots were removed, particularly in the area where the scaffolds had been bent the previous season. The three other systems were summer pruned during the first week in June. Dominance of the scaffolds selected during the previous growing season and/or during the dormant season was reinforced by removing all vigorous competing shoots. A shoot growing near the terminal of each scaffold was selected for continued extension of the scaffold in the desired direction. Large branches in the lower area of the tree canopy were removed, but no further fruit-wood selection was made.

Fruit clusters were thinned in May, particularly in the branch crotch areas where space available for expansion was limited. Fruit were harvested in one picking in early August

Yearthree. All orchard systems were pruned in the middle of Dec. 1991. In the Cordon system, low, shaded limbs and vigorous, upright shoots were removed, and fruiting wood was thinned. In the two V systems, a vigorous shoot was selected to continue the development of each scaffold, and all vigorous (water sprout type) shoots that might compete with the terminal shoot or shade out other fruiting wood were eliminated. Moderate-sized fruiting wood $(0.3-0.5 \mathrm{~m}$ long $)$ originating directly from the two scaffolds was selected to bear the 1992 crop. After pruning, $\approx 80$ fruiting shoots remained per tree. The $\mathrm{V}$-shaped trees were not headed. In the Open Vase system, vigorous shoots were selected to fill out the walls of the vase and other vigorous shoots were eliminated. Fruiting wood similar to that kept in the $\mathrm{V}$ systems was also selected and retained on the structural scaffolds. These trees were lightly headed at $\approx 2.5-3 \mathrm{~m}$.

All four orchard systems were suckered on 31 Mar.-2 Apr. 1992 by removing root suckers and vigorous upright shoots arising from the crotch area. The Cordon system was summer pruned at the end of April and after harvest in August; rapidly growing, vigorous, upright shoots were removed, particularly in the area where the scaffolds had been bent during the first season.

The three other systems were not summer pruned until shortly after harvest in August. Dominance of the scaffolds that had been selected during the previous growing season and/or during the dormant season was reinforced by removing vigorous competing shoots. Large branches in the lower area of the tree canopy were removed, but no further fruit wood selection was made. This summer pruning was done without ladders.

In early summer, Open Vase trees with large crops were tied with tree rope at $\approx 2.5 \mathrm{~m}$ aboveground to prevent excessive spreading. Additionally, the west scaffold of a few Vshaped trees was tied to the tree in the adjacent tree row to maintain the spread in the $\mathrm{V}$ shape of the trees that had grown too upright. This problem was encountered mainly in the north side of the orchard where northwest winds had blown the vigorous scaffolds into an upright position.

Fruit were thinned in late Apr. 1992. At the beginning of the growing season, based on the size of the trees and the amount of fruit wood ("hangers") remaining after pruning, $40 \mathrm{t} \cdot \mathrm{ha}^{-1}$ was set as the goal for yield in the KAC-V system $(\approx 80$ hangers per tree with $\approx 3.5$ fruit per hanger and 6.6 fruit $/ \mathrm{kg}$ ). These trees were thinned accordingly. The Cordon system was thinned to leave the same number of fruit per hectare as in the KAC-V, and the HiD KAC$\mathrm{V}$ system to leave approximately the same number of fruit per tree. The greater number of trees per hectare in the latter system produced a larger number of fruit per hectare. Fruit thinning in the Open Vase trees consisted of breaking up clusters, leaving enough space between fruit so that they would not push each other off the branches later in the season as they sized.

The fruit were harvested in two pickings on 22-23 July and 28-29 July. Yields were determined by picking the fruit into bin trailers with load cells mounted around the axles and tongue and recording the weight of fruit removed from each system subplot. One border row around each system subplot was excluded from the harvest data to eliminate edge effects. Yield data reflect the amount of fruit delivered to the receiving station, where total off-grade percentage was $<1 \%$. Small and insect-damaged fruit were discarded in the orchard and therefore not accounted for in yield data (discarded fruit were estimated to be $<5 \%$ of the total). Mean fruit weight was estimated by randomly counting and weighing a minimum of 20 boxes of fruit per subplot per pick.

Years four and five. All trees were pruned in the middle of Dec. 1993 and 1994. Again, pruning of the Cordon system was the least intensive because of intensive summer pruning the previous season, and included removal of lower, weak, shaded limbs and strong, upright shoots that grew after the last summer pruning. The upper ends of tall shoots were headed to side shoots to allow management from the ground. With the two V systems, all vigorous (water sprout type) shoots that might compete with the terminal shoot or shade out fruiting wood were eliminated. About 100 moderate-sized fruiting shoots $(0.3-0.6 \mathrm{~m}$ in length) originating as close to the two scaffolds as possible were selected to bear the next season's crop. No attempt was made to restrict the $\mathrm{V}$ trees to a specific height; some trees were 4.0 to $4.5 \mathrm{~m}$ tall. The tops of the scaffolds were headed to weak upright lateral branches to avoid stimulating vigorous growth. Open Vase trees were pruned to strengthen existing scaffold branches and eliminate vigorous shoots, inside and outside the vase, that would compete with selected scaffolds or shade fruiting wood. Moderate-sized fruiting wood ( $0.3-$ $0.6 \mathrm{~m}$ long) was selected as in the V systems. Large, extensively branched "hangers" were not allowed to develop.

In Feb. 1993, in anticipation of large crop loads during the following season, a rope was looped around the two scaffolds on all V trees. All Open Vase trees that had not been roped previously were roped at $\approx 2.5 \mathrm{~m}$ from the ground by encircling all major scaffolds on the tree. A second rope was added $\approx 0.5 \mathrm{~m}$ above the existing one in Feb. 1994. The V trees were roped by looping a rope around the two scaffolds on individual trees. In both tree types some slack was left in the rope to accommodate the desired amount of spreading with crop load. Roping costs were included in pruning costs. 
All four systems were summer pruned in mid-April without using ladders. Root and crown suckers were removed and all vigorous upright water sprouts that could be reached from the ground were removed. This operation took about twice as much time for the Cordon compared to the $\mathrm{V}$ systems because the former tended to produce vigorous upright shoots on the upper side of the horizontal cordons. The Cordon system received a second extensive summer pruning in mid-June 1993 and early July 1994. During this pruning, the second set of current season water sprouts was removed.

After harvest in 1993, all systems were summer pruned again. This pruning in the Cordon and Open Vase systems was quite modest and done entirely from the ground. Only vigorous upright shoots in the center of these trees were removed. In contrast, this pruning in the $\mathrm{V}$ systems was quite extensive and involved ladders. The $\mathrm{V}$-system trees were quite vigorous, even with heavy crop loads. Several water sprout-type shoots had developed on the terminal ends of each scaffold and were shading the lower fruiting wood. We therefore removed all but one of these vigorous shoots on each scaffold.

Within a month after harvest in 1994, the Cordon system was summer pruned as in 1993 and the other three systems were mechanically topped at $\approx 4.1 \mathrm{~m}$.

In 1993 and 1994 fruit set was light in the Cordon system. The objective of thinning was only to break up clusters of fruit and reduce the number of fruit on obviously weak hangers. The KAC-V trees were thinned as in 1992 but $49(\approx 350$ fruit/tree and 6.6 fruit $/ \mathrm{kg})$ and 67 $\mathrm{t} \cdot \mathrm{ha}^{-1}(\approx 480$ fruit $/$ tree and 6.6 fruit $/ \mathrm{kg}$ ) were set as the yield goals for each year, respectively. Trees in both V systems were thinned to approximately the same number of fruit per tree, but the number of fruit per hectare was greater in the HiD KAC-V system because of the greater number of trees per hectare. Fruit thinning in the Open Vase trees consisted of spacing fruit to $10-12 \mathrm{~cm}$ where possible. Fruit were harvested in three pickings in 1993 (2829 July, 2-5 Aug., and 6-9 Aug.) and two pickings in 1994 (1-4 and 8-11 Aug.). Harvest data were collected in the same manner as in 1992.

Financial analysis. The number of workerhours needed to accomplish each orchard operation (i.e., spraying, mowing, brush shredding, etc.) was calculated by recording the time required to perform each operation on several rows of each system. This was multiplied by the labor cost of mechanical operations in $1990(\$ 8.50 / \mathrm{h})$ to calculate the labor costs. Similarly, the number of worker-hours needed for each hand-labor operation was calculated by monitoring the worker-hours spent in each system subplot for each operation. Crew sizes ranged from two to 16 , depending on the task. The number of worker-hours required to accomplish each hand-labor task was multiplied by $\$ 6.00$ to calculate the labor costs associated with each operation. First-year costs were aggregated from Jan. to Oct. 1990, and subsequent-year costs from November to October. All expenses are reported as system- specific costs on a land area basis. These costs exclude land, equipment, and chemical costs.

To determine the annual crop value, crop yield data for each year were multiplied by the average price per ton of cling peaches in California for the period 1991 to 1994 (\$234.58). All income and cost estimates are reported as net 1990 dollar values using a discount rate of $6.9 \%$, which is the average rate of return on agricultural assets in California during the period 1990-94 (U.S. Dept. of Agriculture, 1994). Cumulative costs and crop values were calculated as the sums of the discounted cash flows (Boehlje and Eidman, 1984). Cumulative gross profit (gross profit before deduction of expenses associated with land, equipment, and chemical costs) was calculated as the difference between cumulative cost and cumulative crop value.

All statistical analyses were carried out using SAS software (SAS Institute, Cary, N.C.), and Duncan's multiple range test was used for multiple means separations.

\section{Results}

System-specific costs during the first year (Fig. 1) were dominated by initial establishment costs, including cost of trees $(\$ 3.49$ per tree), planting ( $\$ 0.41$ per tree by commercial contractor),initial pruning (@ $\$ 6.00$ perworker hour) and installation of tree protectors (@ $\$ 0.025$ plus labor). Costs per hectare were directly proportional to tree density, since the commercial nursery and planter did not offer price breaks for high-density plantings. Tree training costs per hectare in the first year varied from zero in the Open Vase system to $\$ 800$ (\$750 using discounted dollars) for the Cordon system. General maintenance costs were $<\$ 742$.

System-specific costs during the second year (Fig. 2) were relatively small compared with those during all other years of the study. Costs for mechanized operations (general maintenance) accounted for about half of the costs for each system. Fruit thinning and harvest costs in this year were greater for the Cordon system because it had the greatest fruit set and yield (6.0 vs. $<2.0 \mathrm{t} \cdot \mathrm{ha}^{-1}$ for the other three systems).

In the subsequent 3 years the majority of system-specific costs, regardless of system, were associated with thinning and harvesting the crop (Fig. 2). The Cordon system generally had the highest summer pruning costs but the lowest dormant pruning costs. Fruit thinning and harvest costs were generally related to crop load (Table 1). Cumulative expenses over the 5 years of this trial were consistently highest for HiD KAC-V, the highest density system (Fig. 3). Cumulative costs of establishment and maintenance were higher for the Cordon than for the KAC-V system (at the same tree density) over the first 3 years. In the fourth year, the cumulative costs for the Cordon system were lower than for the V systems. By the fifth year there were no significant differences between the cumulative costs of the Cordon and the KAC-V systems.

Although the harvest efficiency of the Cordon system tended to be higher than that of the other systems in the fourth and fifth years (Table 2), when yields of the Cordon system approached those of the KAC-V (Table 1), the differences were significantly different only in the fifth year.

Of the four systems, the HiD KAC-V system produced the highest annual crop value except in the second year (Fig. 3B). Although the Cordon system out-produced the other three systems in 1991, it lagged behind the V systems in 1992 and 1993. The Open Vase system had the lowest annual crop values in

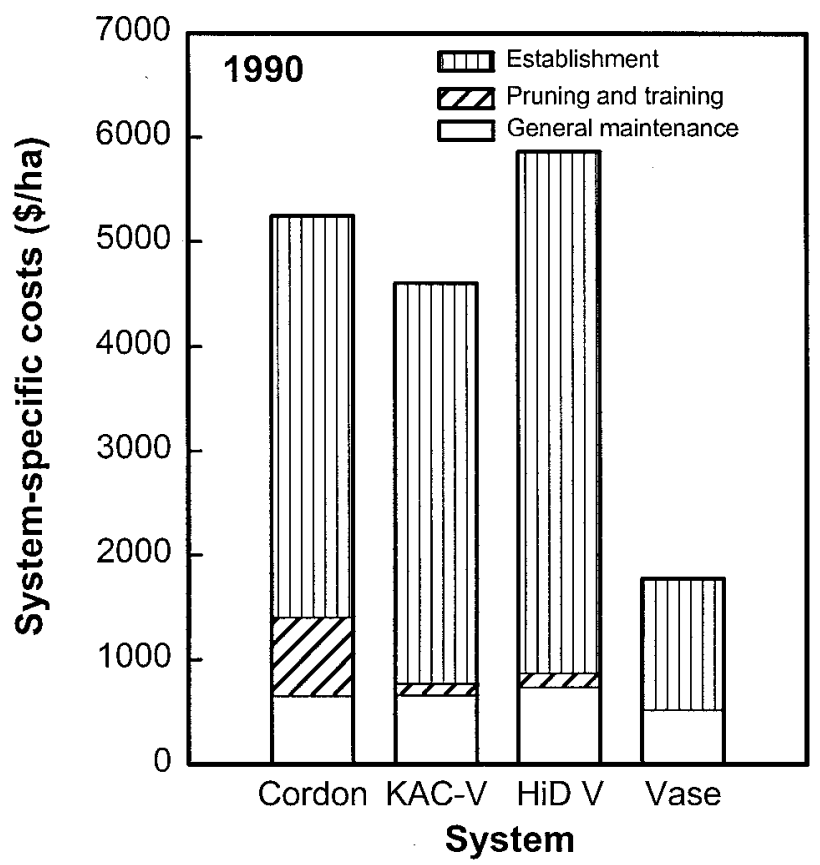

Fig. 1. Summary of system-specific costs of establishing and maintaining four peach orchard systems (see text for details) with 'Ross' cling peach on 'Nemaguard' rootstock during the first growing season after planting. 


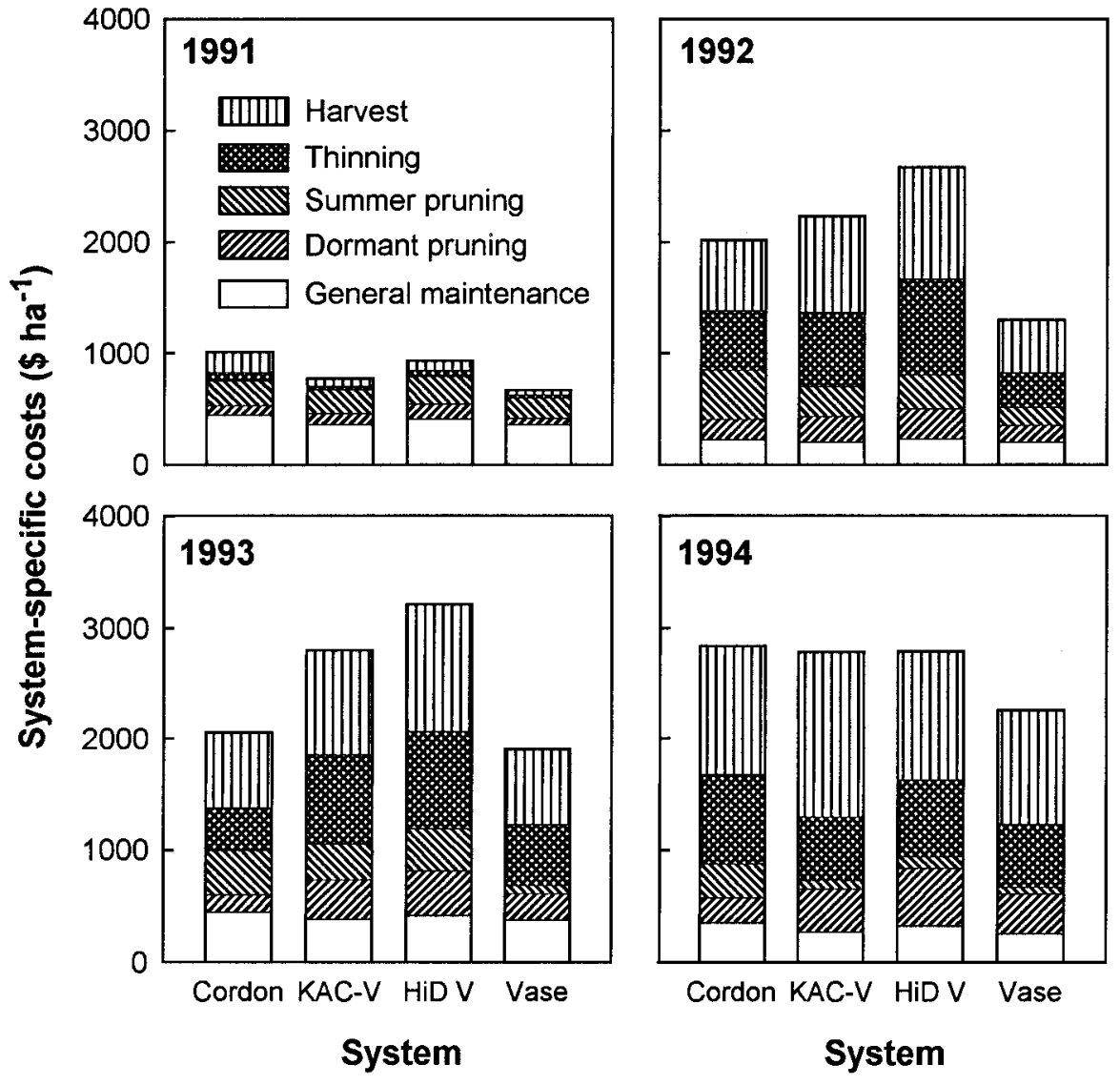

Fig. 2. Breakdown of system-specific costs of establishing and maintaining four orchard systems with 'Ross' cling peach during the second through fifth years after planting (see text for details).

Table 1. Effect of training system on mean annual yield and yield components during years 3,4 , and 5 of production of 'Ross' peach.

\begin{tabular}{|c|c|c|c|c|}
\hline Training system & $\begin{array}{c}\text { Yield } \\
\left(\mathrm{t} \cdot \mathrm{ha}^{-1}\right)\end{array}$ & $\begin{array}{c}\text { Fruit no. } \\
\text { (1000 fruit/ha) }\end{array}$ & $\begin{array}{l}\text { Fruit fresh wt } \\
\text { (g/fruit) }\end{array}$ & $\begin{array}{c}\text { Harvest labor costs } \\
\text { (hours/t) }\end{array}$ \\
\hline & \multicolumn{4}{|c|}{1992} \\
\hline Cordon & $33.3 \pm 1.9 \mathrm{c}^{\mathrm{z}}$ & $207.0 \pm 13.7 \mathrm{c}$ & $161.2 \pm 3.3 \mathrm{bc}$ & $3.8 \pm 0.14 \mathrm{a}$ \\
\hline KAC-V & $45.2 \pm 2.2 b$ & $263.5 \pm 11.9 b$ & $171.7 \pm 3.9 b$ & $3.8 \pm 0.09 \mathrm{a}$ \\
\hline HiD KAC-V & $53.6 \pm 2.5 \mathrm{a}$ & $334.1 \pm 16.2 \mathrm{a}$ & $159.8 \pm 1.4 \mathrm{c}$ & $3.8 \pm 0.11 \mathrm{a}$ \\
\hline \multirow[t]{2}{*}{ Open Vase } & $25.7 \pm 1.1 \mathrm{~d}$ & $138.1 \pm 5.2 \mathrm{~d}$ & $186.0 \pm 4.9 \mathrm{a}$ & $3.7 \pm 0.12 \mathrm{a}$ \\
\hline & \multicolumn{4}{|c|}{1993} \\
\hline Cordon & $45.8 \pm 1.6 \mathrm{c}$ & $255.9 \pm 7.4 \mathrm{c}$ & $179.0 \pm 2.4 \mathrm{ab}$ & $3.2 \pm 0.20 \mathrm{a}$ \\
\hline KAC-V & $58.3 \pm 3.2 \mathrm{a}$ & $330.7 \pm 22.2 b$ & $177.0 \pm 5.7 \mathrm{ab}$ & $3.5 \pm 0.27 \mathrm{a}$ \\
\hline HiD KAC-V & $68.1 \pm 2.3 \mathrm{a}$ & $407.1 \pm 16.8 \mathrm{a}$ & $167.6 \pm 5.0 \mathrm{~b}$ & $3.6 \pm 0.22 \mathrm{a}$ \\
\hline \multirow[t]{2}{*}{ Open Vase } & $44.3 \pm 1.2 \mathrm{c}$ & $232.0 \pm 6.6 \mathrm{c}$ & $191.1 \pm 4.0 \mathrm{a}$ & $3.3 \pm 0.16 \mathrm{a}$ \\
\hline & \multicolumn{4}{|c|}{1994} \\
\hline Cordon & $58.7 \pm 2.4 \mathrm{~b}$ & $367.0 \pm 10.6 \mathrm{a}$ & $159.7 \pm 3.5 \mathrm{a}$ & $4.0 \pm 0.10 \mathrm{c}$ \\
\hline KAC-V & $62.7 \pm 3.7 \mathrm{ab}$ & $382.7 \pm 31.8 \mathrm{a}$ & $165.0 \pm 5.9 \mathrm{a}$ & $4.3 \pm 0.34 b c$ \\
\hline HiD KAC-V & $68.5 \pm 2.8 \mathrm{a}$ & $399.9 \pm 24.2 \mathrm{a}$ & $171.9 \pm 3.4 \mathrm{a}$ & $5.0 \pm 0.07 \mathrm{a}$ \\
\hline Open Vase & $56.6 \pm 1.7 b$ & $347.9 \pm 9.5 \mathrm{a}$ & $162.8 \pm 1.9 \mathrm{a}$ & $4.7 \pm 0.10 \mathrm{ab}$ \\
\hline
\end{tabular}

${ }^{2}$ Mean separation within columns and years by Duncan's multiple range test, $P \leq 0.05$.

1992 and lower crop values than the V systems in 1993 and 1994. Even though the HiD KACV system yielded the highest mean cumulative crop values for the 5-year period (Fig. 3C), the cumulative gross profit for the two $\mathrm{V}$ systems did not differ significantly (Fig. 3D) because of the difference in annual costs associated with each system (Fig. 3A). Similarly, although the cumulative crop value was significantly greater for the Cordon system than for the Open Vase system (Fig. 3C), cumulative gross profits were similar (Fig. 3D) because of the relatively high establishment and maintenance costs of the Cordon system.

Even though tree height was maintained low enough to eliminate the need for ladders in the Cordon system, no economic advantage was realized in the broad comparison of all the systems. Obviously the differences in annual crop values (Fig. 3C) between the systems were directly related to crop yield. Although individual fruit weight was not recorded in 1991 (Year 2), field observations indicated that differences in yield were clearly related to fruit number. Although there was a consistency in the rank order of crop yield and fruit number between the four systems in all four years, the same was not true of fruit size. For example, in 1992 mean fruit weights in the Cordon and KAC-V systems were similar even though fruit numbers were substantially greater in the latter system. Conversely, in 1994, fruit numbers and fruit weights were similar among all systems.

\section{Discussion}

Evaluations of pruning/training systems are usually limited to comparisons of physiological or horticultural efficiency, expressed as yields per trunk cross-sectional area or per unit of land area, with little consideration for the economics of establishing or maintaining the systems. More complete economic evaluations are relatively rare because of the difficulty and expense of conducting replicated field trials that are large enough to obtain sound data. This study clearly demonstrates the value of including economic data in evaluations of the efficiency of orchard management systems. In this study, the system with the highest cumulative crop yield (Fig. 3C) over the first 5 years (HiD KAC-V) also had the highest initial establishment and annual maintenance costs. When the system-specific costs were deducted from the crop value, there were no statistically significant differences between the net returns from this system vs. those of the next highest yielding system (the KAC-V, Fig. 3D). Similarly, the Cordon system had significantly higher yields than the Open Vase system in years 2 and 3 of the study and comparable yields in years 4 and 5 (Fig. 3A). However, cumulative gross profits were similar to those for the Open Vase system by the fifth year (Fig. 3D) because of large differences in cumulative system expenses (Fig. $3 \mathrm{~A}$ ) without sufficient offsetting increases in cumulative crop value (Fig. 3C).

On the other hand, under the conditions of this experiment there were no statistically significant disadvantages of the HiD KAC-V system vs. the KAC-V system or of the Cordon system vs. the Open Vase system (Fig. 3D), in spite of significant and substantial differences in cumulative costs (Fig. 3A). However, absolute comparisons of the economics of each system are subject to problems similar to comparisons of the horticultural yield efficiency of different systems at different sites. In making these economic comparisons we chose to use constant labor costs of $\$ 6.00$ and $\$ 8.50$ per worker-hour for hand work and machine operation, respectively. These values were comparable to what some growers were paying at the outset of the study. Similarly, the crop value we used $(\$ 234.58 / \mathrm{t})$ was the mean negotiated price received for the cling peach crop over the last 4 years of the study. Higher costs of labor relative to the price received for the crop would have favored the systems with lower crop production and maintenance costs (Open Vase and KAC-V). On the other hand, higher prices for the crop, such as could be expected for fresh-market peaches, would in- 

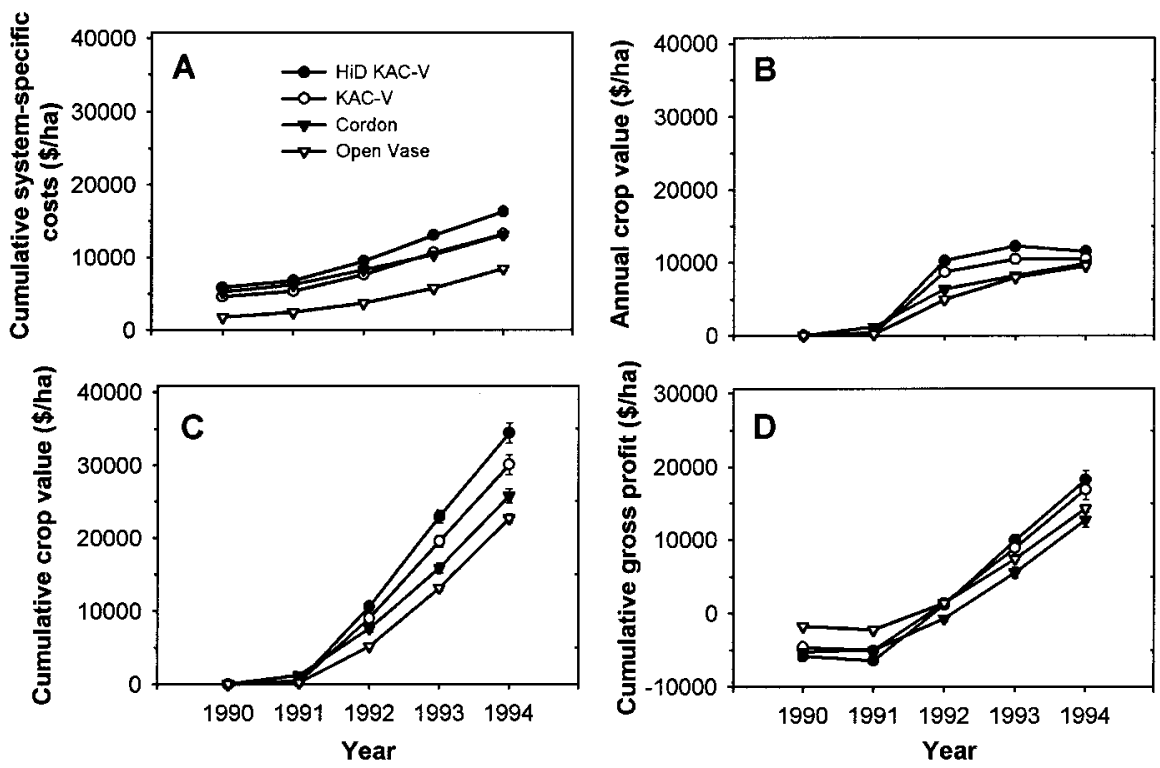

Fig. 3. Cumulative system-specific costs establishment maintenance costs (A), annual crop values (B), cumulative crop values $(\mathbf{C})$, and cumulative gross profits (D) from four orchard systems with 'Ross' cling peach over the first 5 years after planting (see text for details). Symbols represent means of four replicate plots. Standard errors are within the symbols. Dollar amounts represent net 1990 values using a discount rate of $6.9 \%$.

Table 2. Effect of training system on harvest labor costs (worker-hours/t) during years 3, 4, 5 of production of 'Ross' peach.

\begin{tabular}{lllll}
\hline \hline & \multicolumn{4}{c}{ Training system } \\
\cline { 2 - 5 } Year & Cordon & KAC-V & HiD KAC-V & Open Vase \\
\hline 1992 & $3.8 \pm 0.14 \mathrm{a}^{\mathrm{z}}$ & $3.8 \pm 0.09 \mathrm{a}$ & $3.8 \pm 0.11 \mathrm{a}$ & $3.7 \pm 0.12 \mathrm{a}$ \\
1993 & $3.2 \pm 0.20 \mathrm{a}$ & $3.5 \pm 0.27 \mathrm{a}$ & $3.6 \pm 0.22 \mathrm{a}$ & $3.3 \pm 0.16 \mathrm{a}$ \\
1994 & $4.0 \pm 0.10 \mathrm{c}$ & $4.3 \pm 0.34 \mathrm{bc}$ & $5.0 \pm 0.07 \mathrm{a}$ & $4.7 \pm 0.10 \mathrm{ab}$ \\
\hline
\end{tabular}

${ }^{\mathrm{z}}$ See Table 1.

crease the importance of yield relative to production and maintenance costs. Given the difficulties in predicting the outcome of new plantings, and the relationship between labor costs and prices received for the crop, one can understand why California growers have been relatively slow to adopt new peach planting/ training systems that have high initial costs.

The results of this study on peach in California are similar to the situation reported by Jackson et al. (1986) for apple in England. English growers also tended to favor semiintensive apple plantings over high-intensity systems. An economic analysis of the two types of systems indicated that, although early yields were higher in highly intensive systems, their higher establishment and maintenance costs made the marginal profit from those systems only slightly better. Given the variability in crop price and annual cropping, a strong case for the more intensive systems was difficult to make.

The importance of understanding the balance between costs and yield is best illustrated by examining the Cordon system. The Cordon system was initiated primarily with the intention of decreasing labor costs by lowering the height of the trees while maintaining yields equal to or greater than the conventional Open Vase system. The initial tying down of the scaffold limbs (establishing the Cordon) increased training costs in the first year relative to the KAC-V (a system at the same density,
Fig. 1) and increased crop in the second year relative to all three other systems (6 vs. $<2$ $\left.\mathrm{t} \cdot \mathrm{ha}^{-1}\right)$. However, the system did not yield as well as the KAC-V system in years 3 and 4 of the study (Table 1, Fig. 4). Statistically significant increases in harvest efficiency (workerhours per ton) were not realized for the Cordon system, even though ladders were not required for harvest. The reason for this may have been the increase in vegetative growth in Cordon trees compared to the other systems (Grossman and DeJong, 1998), as well as the relative differences in yield components, since the Cordon trees generally produced smaller fruits than did the other systems (Table 1). Conversely, tall ladders were used for all handwork operations in the $\mathrm{V}$ and Open Vase systems, and worker efficiency might be increased in the $\mathrm{V}$ systems by using movable platforms.

The low yields of the Cordon system relative to the V systems in 1992 and 1993 were mainly a function of low fruit numbers per hectare (Table 1). The tying down of the Cordons tended to increase flowering and fruiting in 1991, and to increase growth of vigorous upright shoots at the expense of fruit production on horizontal shoots. These upright shoots tended to continue growing later in the season, formed few flower buds, and set few fruit the subsequent year. Not until 1994, when semipermanent upright scaffolds with productive horizontal fruiting shoots were encouraged to develop off the cordons, did fruit loads and crop yields rise to a level comparable to that of the KAC-V trees planted at the same densities. The Cordon system did not compensate for low fruit numbers with increased fruit size as did the Open Vase trees, suggesting that the fruit were unable to compete for nutrients as effectively as in the other systems (Grossman and DeJong, 1995), possibly because of increased competition from vegetative growth (Grossman and DeJong, 1998).

One of the advantages of high-density systems is that maximum yield capacity is attained earlier than in low density systems (Jackson, 1985). This is documented in the present study (Fig. 4). The HiD KAC-V system appeared to have attained its maximum yield potential (annual crop value) by the fourth year, the KAC-V system by the fifth year; however, it is difficult to judge when yields of the Cordon and Open Vase systems would level off. Yields in the Cordon system increased linearly in the last 3 years and did not follow a trajectory similar to the other three systems (Fig. 4), possibly because of the midtrial adjustments in pruning style made to obtain a more regularly productive population of fruiting shoots. Although the economic part of the study ended in 1994, harvest data were obtained in 1995. Yield of the HiD KAC-V, $\mathrm{KAC}-\mathrm{V}$, Cordon and Open Vase systems in 1995 were $56.3 \pm 1.72,52.7 \pm 0.48,38.6 \pm 1.47$ and $41.8 \pm 1.22 \mathrm{t} \cdot \mathrm{ha}^{-1}$, respectively, $82 \%, 83 \%$, $65 \%$, and $75 \%$ of the yield obtained for the same systems, respectively, in 1994. The lower yields in 1995 were generally attributable to poor weather during the bloom and fruit set period. However, the reductions were greater for the Cordon and Open Vase systems than for the $\mathrm{V}$ systems, indicating that the former may have approached their maximum yield capacity in 1994.

In addition to comparing the various systems relative to annual and cumulative crop values and gross costs, our data can also be used to evaluate the relative importance of the various costs. The high establishment costs of the high-density systems were expected since many were incurred on a per tree basis. Under some circumstances commercial nurseries give a price break for trees going into high-density plantings. However, this was not available for this planting.

Although the relatively high costs for pruning, fruit thinning, and harvest are probably not surprising for most fruit growers, the data are quite striking from a research perspective. In the last 3 years, costs associated with fruit thinning and harvest generally accounted for more than two-thirds of the system specific costs. Pruning costs were generally similar to fruit thinning costs in most cases except in 1993, when they were nearly twice the thinning costs for the Cordon system and one-third the thinning costs for the Open Vase system. The relatively high summer pruning costs of the Cordon system reflect the tendency for vigorous water sprout growth (Grossman and DeJong, 1998). This disadvantage of the Cordon system apparently outweighs the potential 
for increased hand labor efficiency because of reduced tree height.

Given the relatively high cost of handlabor operations (pruning, thinning, harvest) compared with general maintenance operations (weed and pest control, fertilization, etc.), one key to substantially increasing profits would be to reduce the need for hand labor. Perhaps more research emphasis should be placed on this area rather than on the enhancement of crop yields as a means of increasing orchard production efficiency.

\section{Literature Cited}

Bargioni, G., F. Loreti, and P.L. Pisani. 1983. Performance of peach and nectarine in a high density systems in Italy. HortScience 18:143-146.

Bargioni, G., F. Loreti, and P.L. Pisani. 1985. Ten years of research on peach and nectarine in high density systems in the Verona area. Acta Hort. 173:299-309.

Boehlje, M. and V.R. Eidman. 1984. Farm management. Wiley, New York.

Chalmers, D.V., B. van den Ende, and L. van Heek. 1978. Productivity and mechanization of the Tatura trellis orchard. HortScience 13:517-521.

Couvillon, G.A. and A. Erez. 1979. A preliminary evaluation of the meadow orchard for peach production. Compact Fruit Tree 12:82-84.

DeJong, T.M., K.R. Day, J.F. Doyle, and R.S.
Johnson. 1994. The Kearney Agricultural Center perpendicular "V" (KAC-V) orchard system for peaches and nectarines. HortTechnology 4:362-367.

DeJong, T.M. and Y.L. Grossman. 1995. Quantifying sink and source limitations on dry matter partitioning to fruit growth in peach trees. Physiol. Plant. 95:437-443.

Denby, L.G., M. Meheriuk, and R. Brownlee. 1988. Effect of training system on yield in 'Early Redhaven' peach. Fruit Var. J. 42:49-52.

Erez, A. 1978. Adaptation of the peach to the meadow orchard system Acta Hort. 65:245250.

Goedegebure, J. 1986. Investment decisions and planting density. Acta Hort. 160:361-370.

Grossman, Y.L. and T.M. DeJong. 1998. Training and pruning system effects on vegetative growth potential, light interception and cropping efficiency in peach trees. J. Amer. Soc. Hort. Sci. 123:1058-1064.

Horton, B.D. 1988. Y-shaped high-density peach trees for increased mechanization potential, $\mathrm{p}$. 412-417. In: N.F. Childers and W.B. Sherman (eds.). The peach, world cultivars to marketing. Horticultural Publ., Gainesville, Fla.

Hutton, R.J., L.M. McFadyen, and J.L. Warwick. 1987. Relative productivity and yield efficiency of canning peach trees in three intensive growing systems. HortScience 22:552-560.

Jackson, J.E. 1985. Future fruit orchard design: Economics and biology, p. 441-459. In: M.G.R. Cannell and J.E. Jackson (eds.). Trees as crop plants. Inst. Terrestrial Ecol. Titus Wilson, London.

Jackson, J.E., G.C. White, and C. Duncan. 1986 Economic appraisal of orchard of Cox's Orange Pippin apple on M.9 and MM.106 rootstocks. Acta Hort. 160:383-390.

Micke, W., A.A. Hewitt, J.K. Clark, and M. Gerdts. 1980. Pruning fruit and nut trees. Univ. of California Div. of Agr. Sci. Lflt. 21171.

Parry, M.S. 1982. Cash flow studies on three orchard systems for Cox. East Malling Res. Sta. Rpt. for 1981:185-191.

Rogers, H.T. 1986. Stick with cling peaches. Western Fruit Grower 106(12)12B-12C.

Sansavini, S., L. Corelli, and L. Giunchi. 1985. Peach yield efficiency as related to tree shape. Acta Hort. 173:139-158.

Stephens, C.P. and J.A.H. Nicholson. 1978. The economics of intensive orchards in the United Kingdom. Acta Hort. 65:31-39.

Taylor, B. 1988. High density systems in Illinois, $p$ 491-498. In: N.F. Childers and W.B. Sherman (eds.). The peach, world cultivars to marketing. Horticultural Publ., Gainesville, Fla.

U.S. Dept. of Agriculture. 1994. Farm Business Economics Report, 1994. Econ. Res. Serv., U.S. Dept. Agr. ECI-1995.

van den Ende, B., D.J. Chalmers, and P.H. Jerie. 1987. Latest developments in training and management of fruit crops on Tatura trellis. HortScience 22:561-568

Winter, F. 1986. Modeling the biological and economic development of an apple orchard. Acta Hort. 160:353-360. 